\title{
História Oral e memória: movimentos sociais de mulheres camponesas ${ }^{*}$
}

\author{
Cristiani Bereta da Silva** \\ Maria Ignez Paulilo**
}

"A luz é outra..."

Foi sob este título que Florestan Fernandes, considerado um dos maiores sociólogos brasileiros e, naquele momento, exercendo o cargo de deputado federal pelo Partido dos Trabalhadores, analisou os ventos que sopravam como novos, em texto publicado no jornal Folha de São Paulo, em 6 de abril de 1992 (Seção Opinião). A década de 1990 havia chegado e com ela a noção de que o Brasil havia passado por mudanças significativas em sua "transição democrática" (iniciada, em 198 5, com o fim da ditadura militar). No Brasil, os anos 1980 haviam sido atravessados (ou sacudidos) por inúmeros movimentos sociais de lutas e de contestações, movimentos rurais ou urbanos, movimentos esses diferentes, mas, em sua grande maioria, buscando maior igualdade social e mais democracia.

* Versão ampliada de trabalho apresentado na Mesa "Historia Oral y subjetividad: investigaciones y cuestiones metodológicas" no evento: XII Jornadas Interescuelas Departamentos de História, realizado no período de 28 a 31 de outubro de 2009, na Universidad Nacional del Comahue, em San Carlos de Bariloche, Provincia de Rio Negro, Argentina.

** Professora Associada do Departamento e Programa de Pós-Graduação em História da Universidade do Estado de Santa Catarina (UDESC).

*** Professora Titular do Programa de Pós-Graduação em Sociologia Política da Universidade Federal de Santa Catarina (UFSC) 
Foi na ação desses movimentos que Florestan Fernandes vislumbrou no horizonte uma nova direção, prenúncio de "novos tempos". No referido texto, o autor fez menção especial ao acontecido no Dia Internacional das Mulheres, quando "uma massa" de agricultoras praticamente invadiu o Congresso Nacional e exigiu a regulamentação do direito à licença maternidade para as mulheres rurais. Como disse o então deputado, as mulheres não foram lá para pedir, mas para reivindicar, deixando isso bem claro através do discurso "cortante e desafiador" da Deputada Luci Choinaski, que, por seu passado camponês e por sua ligação com os movimentos de mulheres agricultoras, tornou-se porta-voz das militantes.

O momento em que o Congresso Nacional se vê invadido por milhares de mulheres, em sua maioria agricultoras, logo, vindas da roça, é emblemático do período da história do movimento das mulheres camponesas no Brasil. Interpretamos esse acontecimento como chave para o entendimento desse momento histórico. Luci fala de três mil mulheres "cercando" os Deputados no Congresso. Em entrevistas realizadas em outras circunstâncias, com mulheres militantes do Movimento de Trabalhadores Rurais Sem Terra - MST ${ }^{1}$, percebemos que esta mobilização, em especial, marcou as experiências de lutas do período, fixando memórias e sentidos, sendo citada como uma espécie de marco temporal e social em diferentes trajetórias de luta e de vida.

O presente trabalho representa um esforço de análise e interpretação da história do Movimento de Mulheres Agricultoras de Santa Catarina - MMA, surgido no Oeste catarinense, em 1983, até sua transformação, no ano de 2004, em Movimento de Mulheres Camponesas - MMC, por conta de sua ligação com a Via Campesina ${ }^{2}$. Nossa análise parte das memórias de duas de suas principais interlocutoras, Luci Choinaski e Adélia Schmitz, que viveram o movimento de formas distintas. Nessa operação,

1 Entrevistas realizadas entre 1997 e 2002 para a pesquisa de Tese de Doutorado em História de Cristiani Bereta da Silva, publicada em livro no ano de 2004 (Silva, 2004).

2 Essa organização constituiu-se em maio de 1993, durante a Primeira Conferência da Via Campesina, realizada na Bélgica. A segunda conferência aconteceu em 1996, no México; a terceira, em 2000, na Índia; e a quarta, em 2004, em São Paulo. A Via Campesina é uma organização internacional, que procura desenvolver a solidariedade e unidade entre organizações camponesas, trabalhadores agrícolas, mulheres rurais e comunidades indígenas e negras da Ásia, África, América e Europa. Tem entre seus principais objetivos a defesa da soberania alimentar, ou seja, do direito dos povos de decidir sobre sua política agrícola e alimentar. Disponível: www.viacampesina.org. Acesso em 3/3/2009. 
debruçamo-nos sobre diferentes entrevistas realizadas entre 2000 e 2008, textos da própria Luci e também transcrições autorizadas de depoimentos, palestras e conferências por elas realizadas em variadas situações. Com relação a Luci, contamos também com uma breve biografia escrita por Rosemeri Laurindo (1992). Certamente o entorno da história dessas duas militantes não se reduz ao dos movimentos sociais, pois que as relações possíveis ampliam o horizonte, oportunizando reflexões e análises sobre a própria história recente do Brasil. A história e as memórias individuais dessas mulheres são também parte da história das mulheres camponesas, da vida no campo, dos movimentos sociais de luta pela terra e dos direitos das mulheres, da história política e das políticas públicas de um Brasil, que, nos últimos vinte anos, vem sendo construído e reconstruído sobre outras bases, ou, pelo menos, desejos e sonhos de um país efetivamente democrático, com maior igualdade social.

Trabalhamos com a idéia de que as narrativas dessas mulheres sobre suas trajetórias políticas e afetivas são construções sobre passados, sobre histórias e memórias. Nesse sentido, faz-se importante notar que quando nos referimos à trajetória não a estamos entendendo como um conjunto coerente e orientado de relatos lineares de acontecimentos que se sucedem, mas sim como um relato que constrói e reelabora percursos, imagens e representações de si e de eventos que se desviam e se deslocam a todo o momento, inelutavelmente situados a partir dos lugares sociais e culturais ocupados pelos sujeitos. E porque lidamos com memórias, esquecimentos, e provavelmente ocultações, procuramos ter cuidado com o entrelaçamento entre memória e História nas análises das entrevistas e depoimentos orais realizados para a escrita desse artigo.

Certamente que todo o trabalho com as fontes, sejam elas orais ou não, recomenda cuidados e procedimentos específicos por parte do pesquisador. Com as fontes orais não seria diferente, principalmente quando se assume a postura de não tomá-las como evidências factuais, depositário de informações ou mero recurso para preencher lacunas que outras fontes não preenchem, mas sim como narrativas portadoras de significados, sujeitas a elaborações subjetivas, versões e interpretações feitas de lembranças, simulações, esquecimentos e ocultações. Procedimento metodológico, portanto, em que se constroem fontes, interpelando sujeitos, induzindo e estimulando narrativas. Com testemunhos orais lida-se com tempos, memórias, identidades e pertencimentos em seus movimentos 
múltiplos e cadências diferenciadas. Nesse sentido, questões importantes se impõem, como, por exemplo, a construção e também disputas pelas memórias sobre determinados acontecimentos, no caso, aqueles que envolvem e significam o Movimento das Mulheres Agricultoras e a própria militância feminina nas últimas décadas.

O trabalho com as fontes orais na pesquisa Memória e História Oral - Possibilidades interpretativas sobre a história dos Movimentos de Mulheres Camponesas após a década de $1980^{3}$ colocou em relevo questões sobre a memória, ou melhor, sobre memórias, representações e lembranças reconstruídas em diferentes narrativas e a relação com a escrita da História. Lidam-se, aqui, com dimensões que exigem perspectivas diferentes: a História como uma produção discursiva, ou seja, a escrita de uma história a partir de narrativas orais, e, por outro lado, com as representações sobre determinados acontecimentos passados, com memórias pessoais e também com memórias coletivas. Nesse sentido, no exercício de pensar as relações entre História e memórias a partir dessas narrativas orais, buscamos fazer algumas reflexões sobre os sentidos construídos, nas últimas décadas, sobre a memória no interior do campo da História. Empreendemos, aqui, esse exercício apenas para melhor situar o lugar de onde falamos e como percebemos essa relação, afinal a particularidade do lugar é marca indelével na operação histórica, como muito bem destacou Michel de Certeau (1987, p. 17).

É possível afirmar que, desde o momento em que a Historia Oral se estabeleceu como prática, nas décadas de 1960 e 1970, e, de certa forma, também como movimento, pesquisadores e pesquisadoras que trabalham com esta metodologia vêm debatendo os entrelaçamentos entre História e memória. Lembramos que o recrudescimento das discussões sobre a memória - não apenas no âmbito acadêmico, é necessário dizer faz parte do boom de memória, fenômeno espraiado para diferentes lugares do mundo a partir do contexto europeu do pós-Segunda Guerra. O direito e o "dever de memória" foi colocado em pauta exortando as lembranças e interditando o esquecimento do sofrimento das vítimas da guerra,

3 Pesquisa em andamento, desenvolvida no Programa de Pós Graduação em História da UDESC, por ambas as pesquisadoras, numa parceria interinstitucional. O acervo de entrevistas e depoimentos orais pertence ao Núcleo de Estudos sobre Agricultura Familiar/NAF/UFSC, coordenado por Maria Ignez Paulilo. 
principalmente as do Holocausto. Em certa medida, é possível observar que esse direito e dever de memória também foi incorporado, desde então, por diferentes países, em outros contextos políticos. Nesse movimento, questões relacionadas às memórias individuais e coletivas entrariam definitivamente para o campo de estudo, reflexões e análises de diferentes pesquisadores. Mas os historiadores demorariam um pouco mais a tomar parte nessas discussões. Nesse domínio, segundo Philippe Joutard, os historiadores teriam sido amplamente precedidos por sociólogos e etnólogos, pois "foi preciso esperar até 1978 para que Pierre Nora reconhecesse seu valor em La nouvelle Histoire" (Joutard, 1993, p. 526).

A partir do início da década de 1980, o campo disciplinar da História teve suas discussões sobre memória orientadas, sobretudo, a partir das Ciências Sociais, da Psicologia Social e da Filosofia. Devemos a Maurice Halbwachs a evidência da memória em terceira pessoa, ou seja, sua atribuição como coletiva ou social. Suas análises partem das interpenetrações entre memória coletiva e individual e, como contraponto, posiciona-se contra a idéia de uma "memória histórica". Para Halbwachs, História e memória seriam opostas justamente por serem de naturezas diferentes. A memória seria reconstruída sobre o "passado vivido" e estaria, portanto, em movimento, ao contrário da História escrita que, apreende o passado "congelando-o em túmulos" (Halbwachs, 2004, p. 75). Ainda, segundo esse mesmo autor, constroem-se as memórias individuais e coletivas a partir de um tempo e um lugar situados, daí a necessidade de compreender o contexto social de elaboração dessas memórias para torná-las inteligíveis. Embora se possam ter algumas restrições com relação à abordagem a partir da qual tal análise foi formulada (durkheimiana) e a própria concepção de História (historicismo do século XIX) adotada à época pelo autor, seguimos sua orientação quanto à importância do contexto social onde as falas analisadas foram elaboradas, por isso o uso também de fontes não orais.

Diferentes historiadores que retomaram a discussão sobre a memória a partir de leituras de Halbwachs contrapõem-se à coisificação dos fatos históricos, mas partem da oposição formulada por ele para estabelecer deslocamentos sobre a memória e a História. Pode-se dizer que a historiografia incorpora a preocupação com a memória, inscrevendo e validando uma relação entre memória coletiva e História como sendo de oposição e de conflito. "Memória, História: longe de serem sinônimos, 
tomamos consciência que tudo opõe uma à outra" (Nora, 1993, p. 9). Mas será mesmo que tudo opõe uma a outra? "Tudo" é muita coisa, e, em se tratando de testemunhos orais, há muitos pontos entrelaçando a História e a memória.

Segundo Paul Ricoeur, ao se colocar como sujeito de si mesma, a História foi "tentada a abolir o estatuto de matriz de história, geralmente concedido à memória, e a tratar esta última como um dos objetos do conhecimento histórico” (2007, p. 107). Porém, este filósofo observa aí pelo menos duas ordens que se cruzam e concorrem entre si. De um lado, a pretensão de dissolver o campo da memória no da História, por meio do desenvolvimento de uma história da memória, e, por outro lado, a resistência da memória a tal diluição, "graças a sua capacidade de se historicizar sob uma diversidade de figuras culturais" (Idem, p. 397). São universos de discursos que, na operação histórica, ainda subsistem em oposição, sobrepostos ou às vezes alheios um ao outro, mas que evidenciam a falta efetiva de ruptura com a tradição aristotélica, que definiu memória como conhecimento do passado. Outro ponto, considerado como dilema paralisante por Paul Ricoeur, é a polarização entre memória pessoal e memória coletiva, ou seja, sobre quem seria o "sujeito verdadeiro das operações da memória". Sobre essa polaridade, este autor discute a hipótese de um plano intermediário de referência no qual se operariam as trocas entre a memória viva do indivíduo e a memória pública das comunidades às quais pertencem, pois não seria "apenas com a hipótese da polaridade entre memória individual e memória coletiva que se deve entrar no campo da história, mas com a de uma tríplice atribuição da memória: a si, aos próximos, aos outros" (Idem, p. 142).

O trabalho com testemunhos orais evidencia esse movimento, colocando as imbricações dessas atribuições da memória, pois lida com múltiplas temporalidades e representações sobre o passado atualizadas no presente. Ou melhor, embora produzida a partir do presente, a memória é sempre sobre o passado. Nesse plano, a contribuição de Michael Pollak, ao estabelecer outras relações entre memória e História, abre novas possibilidades para o trabalho no campo da História, sobretudo quando se lida com fontes orais. Leitor de Halbwachs, Pollak critica a idéia de coisificação dos fatos históricos, mas reconhece na memória coletiva o caráter potencialmente instigante de situá-la sob outra perspectiva: "Não se trata mais de lidar com os fatos sociais como coisas, mas de analisar 
como os fatos sociais se tornam coisas, como e por quem eles são solidificados e dotados de duração e estabilidade" (Pollak, 1989, p. 4). Para Pollak, a aplicação desta abordagem à memória coletiva seria oportunidade para compreender como as memórias são constituídas e formalizadas no interior dos processos históricos.

Nesse caso, a História Oral, ao privilegiar a análise dos excluídos, dos marginalizados e das minorias, colocaria em relevo as memórias subterrâneas que "se opõem à 'Memória oficial', no caso a memória nacional" (Idem). A emergência destas memórias evidenciaria a disputa entre memórias ou a luta entre a memória oficial e as memórias subterrâneas. Os historiadores trabalhariam, assim, com os conflitos e as disputas nessas "verdadeiras batalhas da memória". E são muitas as memórias em disputa, se considerarmos que numa sociedade existem "memórias coletivas tão numerosas quanto as unidades que compõem a sociedade" (Idem, p. 12). Concordamos, assim, com Verena Alberti (2006), que chama a atenção para o fato de que reconhecer essa multiplicidade seria o melhor caminho a seguir para evitar oposições simplistas entre memória e História ou entre memória oficial e memória individual.

Certamente que as memórias das militantes sobre o MMA são individuais, mas, não obstante isso, devemos considerar que são produzidas também a partir das memórias de outras militantes. Assim como de algum modo retomam (seja para complementar as histórias narradas, contrapôlas ou afirmá-las) outras memórias produzidas em outros lugares, como nos meios de comunicação ou na academia, por exemplo. Para além disso, quando narradas, são reconstituídas considerando outras dimensões, como, por exemplo, qual a memória do movimento e de si que se quer privilegiar em detrimento de outra que se deseja esquecer, interditar? $\mathrm{O}$ que o outro que pergunta, que escuta "minha narrativa", deseja ouvir? O que ele deve ouvir? São questões importantes e que precisamos incorporar em nossas análises.

A abordagem pretendida pela pesquisa realizada, e ainda em andamento, toma as narrativas de Luci Choinaski, Adélia Schmitz e outras militantes do movimento de mulheres agricultoras como práticas políticas, que abrem, assim, perspectivas de interpretação no âmbito da história e do discurso. Parte do entendimento de que são narrativas carregadas de sentidos, atravessadas por representações de passados, portanto, também de memórias sobre a história desse movimento. 


\section{Militâncias...}

Luci e Adélia têm em comum o passado ligado ao campo, a produção familiar agrícola. Fazem questão de afirmar sua "origem camponesa" e as marcas deixadas por esta condição: ambas sofreram na pele as grandes dificuldades pelas quais as famílias de pequenos agricultores brasileiros sempre passaram. Luci, embora gostasse muito de estudar e fosse boa aluna, foi tirada da escola aos 12 anos. Adélia, que também não pôde estudar, teve que trabalhar na cidade, só conseguindo ser novamente agricultora através do casamento. Chamamos a atenção que o acesso a terra por parte das mulheres geralmente se dá, no Sul do país, através do casamento, pois a propriedade rural é dividida preferencialmente entre os filhos homens.

Com uns doze anos meu pai me buscou na sala de aula, eu adorava estudar, chorei tanto que eu perdi a vontade de estudar e de ler, não conseguia ler. Então, foi assim, meu mundo caiu, assim, eu vi me enterrar. Porque o meu sonho era ser professora! Eu vi meu sonho se destruir! E aí eu tive dificuldade de ler, de pegar um texto, sentar, ler. Só que eu fui batalhando pra poder buscar e conseguir me concentrar pra ler e voltar a estudar (Luci Choinaski, em entrevista concedida à Maria Ignez Paulilo e Cristiani Bereta da Silva, em 05/11/2008).

Estudei só até a segunda série do ginásio, isso nos anos 60, aí eu comecei a trabalhar no comércio, porque eu sou camponesa, morava perto da cidade e tive que ajudar os meus pais porque o meu pai era muito doente, aí eu comecei a trabalhar no comércio pra ajudar a sustentar a casa. Sou a segunda de 11 filhos, aí eu queria estudar meio dia e trabalhar meio dia, porque o estudo era só durante o dia na época, não tinha aula à noite, e daí ou eu trabalhava o dia inteiro ou não trabalhava, e assim eu larguei os estudos e só trabalhei. Depois namorei com um agricultor, casei com um agricultor e voltei pra roça. (Adélia Schmitz em palestra na UFSC/Florianópolis, por ocasião da comemoração ao dia 08 de março, 05/03/2007). 
Luci e Adélia inicialmente percorreram o itinerário já traçado, como caminhos historicamente determinados às mulheres que viviam no campo na época. Interromperam seus estudos cedo, pois precisavam ajudar em casa, tanto no trabalho doméstico e na agricultura, a exemplo do caso de Luci, como para contribuir com o sustento da casa por meio de outro trabalho, como foi o caso de Adélia. Casaram-se cedo, tiveram seus filhos: Luci, quatro filhos e Adélia, seis filhos. E, como era esperado, trabalhavam em casa, cuidavam dos filhos e lidavam com a terra. Adélia, além dos filhos, cuidou da sogra, com quem morou por cerca de vinte anos. Mas, em certa altura de suas vidas, conforme demonstram em seus depoimentos, o inconformismo com o que consideravam injustiça fez com que procurassem meios de entender e mudar essa situação.

O primeiro ponto de apoio que encontraram foi a igreja católica progressista, inspirada na Teologia da Libertação. Mas não só Luci e Adélia começaram a "sair de casa" através da igreja. Como mostram Casagrande (1991) e Daboit (1996), esse foi o percurso de imensa maioria das militantes do MMA. Contudo, mesmo esse caminho foi cheio de dificuldades. Zulma, por exemplo, militante que esteve envolvida em diferentes lutas políticas no Oeste na década de 1980, ao conceder uma entrevista, em 2001, no assentamento Conquista na Fronteira, na cidade de Dionísio Cerqueira/SC, disse:

Eu comecei toda a história com as mulheres agricultoras, eu comecei a caminhada na Igreja orientada pelas irmãs, orientada pela pastoral, pelas líderes que vinham nos preparar nesse sentido, da libertação da mulher. E a gente estudava muito a Bíblia pra libertação da mulher. Estudava a história da mulher que se acomodava. [...] Mas começou uma separação maior nessa caminhada, um rompimento do Movimento das Mulheres em relação à Igreja... Mas para a organização das mulheres a Igreja foi muito importante. [...] Falando na questão da Igreja, nos movimentos populares em geral as análises começaram a se aprofundar e daí começou também se rever a história da Igreja nessa questão e daí foi se descobrindo muita coisa que botava em choque o credencial da Igreja, essa questão da espiritualidade, de ser o nosso guia, de ser a orientadora da nossa fé, porque comprometia a sua prática enquanto Igreja. A Igreja também tem uma história de repressão, 
uma história que nos recriminava e não que nos libertava. (Zulma [nome fictício], em entrevista concedida a Cristiani Bereta da Silva, em 09/01/01).

Da mesma forma que Zulma, Luci também teve que se afastar da atuação junto à igreja para poder continuar sua militância política, antes mesmo da criação do Movimento de Mulheres Agricultoras - MMA, em 1983, no Oeste catarinense. Em 1979, quando ainda era ministra da eucaristia, o padre de sua paróquia não queria que ela fosse para um encontro da Pastoral porque esse papel era só dos homens. Luci conseguiu ir, mas, como era a única mulher dentro do carro, teve que suportar o mau humor dos três homens que a acompanhavam. De acordo com suas palavras, "viajaram o tempo inteiro emburrados comigo".

Mesmo sendo a Igreja um lugar sempre permitido para as mulheres, uma coisa era ir à missa aos domingos e, outra, militar dentro da instituição. Da mesma forma, a pressão contrária da família podia ser muito forte, como mostra Adélia.

Eu vinha sendo convidada há muito tempo, porque eu quando jovem sempre fui uma liderança. Eu sempre tive facilidade de captar as coisas. Mas, como eu morei com a sogra, ela não permitia que eu saísse de casa, nem pra catequese, nem pra nada, eu não podia assumir nada. E como eu também criei os meus seis filhos e morei quase 20 anos com a sogra... daí ela morreu, 80 e poucos anos, só depois eu comecei a militar. Então a mulherada me convidava para o movimento, para eu dirigir. A minha sogra morreu em fevereiro, em março, abril eu já fiquei líder da comunidade (Em palestra na UFSC/Florianópolis, por ocasião da comemoração ao dia 8 de março, 5/3/2007).

Apesar das dificuldades e dos limites impostos pela visão que os religiosos tinham sobre o papel das mulheres na sociedade, o trabalho da Igreja no Oeste catarinense, na década de 1980, é lembrado como um marco no processo de "libertação" das mulheres, via Pastoral da Terra e Comunidades Eclesiais de Base, sob a liderança do bispo Dom José Gomes (1921-2002), que, desde a década de 1970, apoiou as mobilizações dos agricultores da região. 
Luci e Adélia se tornaram lideranças nacionais. Vindo ambas do meio rural de Santa Catarina, Luci tornou-se a terceira mulher na história a ocupar o cargo de Deputada Estadual, em 1986, em Santa Catarina, e, na década de 1990, chegou ao Congresso Nacional, fato surpreendente para alguém de origem camponesa. Foi, por dois mandatos (1998-2002 e 2002-2006), eleita deputada federal pelo Partido dos Trabalhadores e, hoje, é presidente desse partido em Santa Catarina. Adélia começou a fazer parte da liderança do MMA em 1991. Iniciou como líder de sua comunidade, "com medo de tudo, sabendo que eu só sabia cozinhar, tirar leite, trabalhar na roça...", como ela mesma afirmou. O medo, porém, não a impediu de assumir a Coordenação Regional, depois a Estadual. Por cinco anos participou da Coordenação Nacional e, em 2007, ano que nos contou sua trajetória, estava terminando seu quarto mandato na Executiva Estadual do MMC.

O MMA foi ganhando força à medida que as mulheres rurais foram tendo acesso a direitos já garantidos para as mulheres urbanas. Possibilidades abertas Constituição de 1988. O reconhecimento das agricultoras como "produtoras rurais", tendo com isso acesso aos direitos previdenciários, foi uma das grandes conquistas dos movimentos sociais rurais, entre eles o MMA. Esses direitos dizem respeito à aposentadoria aos 55 anos, salário-maternidade, auxílio-doença e pensão viuvez. Mas não foi uma conquista que se conseguiu implementar rapidamente. Dois fatores retardaram o acesso: a demora na regulamentação das novas leis e a falta de documentação das mulheres rurais. Um exemplo da demora na regulamentação pode ser visto no caso do salário maternidade, que, embora já estabelecido em 1991, só foi efetivado em março de 1994, apesar da grande mobilização feita, em 1992, em frente ao Congresso Nacional, mobilização que, como já vimos, impressionou positivamente Florestan Fernandes.

Até meados dos anos 1990, a luta pela regulamentação dos direitos trabalhistas garantidos pela constituição foi um grande estímulo para as ações do MMA. A partir desse momento, começou a haver um refluxo na sua forma de atuação mais visível, ou seja, as grandes mobilizações. Dizemos "mais visível" porque o movimento, mesmo em refluxo, manteve uma outra face sua, muito importante, que é a de ser um lugar onde as mulheres conseguem perceber que situações vividas como pessoais são, na verdade, produzidas no e pelo contexto social em que estão inseridas. 
O fato de se reunirem sem a presença masculina que, para elas, é inibidora, faz com que medos e vergonhas, profundamente arraigados, sejam socializados e, através de uma espécie de processo de catarse, tornem-se menos ameaçadores. Esse esforço de verbalização provoca fortes emoções que levam muitas vezes ao choro. Tanto o fato de se reunirem só entre mulheres quanto a liberação de sentimentos reprimidos são bastante criticados por outros movimentos sociais, mesmo pelas mulheres do MST e as sindicalistas. Adélia nos conta em cores vivas como são esses momentos. Seu depoimento é tão contundente que, embora já o tenhamos trazido a público anteriormente, tornamos a reproduzi-lo:

Eu já participei de várias choradeiras, nos encontros. Já participei em muitos momentos que a gente chorava junto com as mulheres, porque pra gente foi emocionante porque tu conseguiu a confiança delas, pra elas falar o que em espaço nenhum elas tinham falado. Isso pra gente é uma conquista, tu conquistar um grupo, falar de coisas que as mulheres choraram e diziam: eu nunca tive coragem de dizer isso aqui em lugar nenhum. E a gente incentivava elas: não, solta tudo, solta tudo, pode falar o que está te atrapalhando, o que está te fechando, solta tudo, porque tu tem o direito de ser uma pessoa livre! E se tu começar a falar, quem sabe as coisas ficam mais fáceis. [...] Agora, se tivesse um homem junto isso teria acontecido? Não teria acontecido, por isso é importante um espaço só para mulheres. Pra mim foi uma grande conquista, eu consegui fazer a pessoa se soltar pra falar, sem ter feito um curso de psicologia. Mas a psicologia tu pode praticar também, tu aprende também fazendo as coisas, né? (Adélia Schmitz, líder nacional do MMC. Entrevista concedida a Maria Ignez Paulilo e Cristiani Bereta da Silva, em 05/03/2007).

Os anos 1990 não foram de mudanças apenas para o MMA. As especialistas em movimentos sociais Ilse Scherer-Warren (2006) e Maria da Glória Gohn (2003) mostram como modificações no contexto político trouxeram mudanças na forma das lutas reivindicatórias. Houve uma institucionalização dos movimentos sociais e, consequentemente, as grandes manifestações públicas foram-se reduzindo. Mas para essas autoras, as mudanças não devem ser traduzidas como enfraquecimento; são formas 
novas e diferentes de organização e atuação que podem trazer inclusive fortalecimento. Scherer-Warren (2006) defende a potencialidade emancipatória que uma das transformações importantes ocorridas - que é a organização, na América Latina, dos movimentos sociais em redes - trouxe quanto à capacidade de articular diversidades regionais, criando utopias que se unificaram através do lema "um outro mundo é possível".

Scherer-Warren faz referência explícita à Via Campesina, que, tendo se expandido através dos foros sociais mundiais, criou, na América Latina, um espaço próprio de articulação política global. Em 2004, foi realizada, no Brasil, a sua IV Conferência Internacional, sob o lema: "Globalizemos a luta, globalizemos a esperança". As questões mais discutidas diziam respeito à soberania alimentar, sementes transgênicas e reforma agrária. A abrangência do encontro pode ser medida pela presença de representantes de organizações camponesas de 80 países, deles da América Latina e Caribe. Deste encontro, ainda segundo a autora, saíram as diretrizes para ações de grande impacto político, que tiveram lugar nos anos subseqüentes, tais como as ocupações dos canteiros da Aracruz Celulose, no Rio Grande do Sul, e a destruição de um de seus laboratórios, em 08 de março de 2006, o que causou grande repercussão na mídia.

Mudanças tão significativas dificilmente poderiam encontrar consenso entre os antigos militantes de qualquer um dos movimentos sociais fortes na década de 1980. O mesmo aconteceu com a filiação do MMA à Via Campesina. Em 1995, houve uma unificação bem sucedida, em nível nacional, dos diferentes movimentos autônomos de mulheres rurais que constituíram a Articulação Nacional dos Movimentos de Mulheres Trabalhadoras Rurais - ANMTR. Nessa articulação, o MMA exerceu papel decisivo, pois a área contínua formada pelo Noroeste do Rio Grande do Sul, Oeste de Santa Catarina e Sudoeste do Paraná congregava as organizações mais atuantes e, por isso, acabaram por dar a direção do movimento em nível nacional. Prova disso foi o fato do MMA ter conservado essa mesma denominação, sem nunca ter-se autodenominado MMTR-SC. Talvez, nesse momento, já começasse a aparecer um germe de dissidência, que fez com que hoje tenhamos pelo menos duas vertentes do movimento de mulheres agricultoras: o MMC e o Movimento de Mulheres Trabalhadoras Rurais do Nordeste, que tem sua sede em Pernambuco MMTR-NE. O relacionamento entre essas duas vertentes se vê ainda prejudicado pelo fato de que algumas lideranças do MMC consideram 
que sua atuação é "mais avançada" politicamente que a dos antigos movimentos autônomos.

O novo contexto modificou também, de forma diferente, a visão que nossas duas entrevistadas, Luci e Adélia, têm da importância da transformação do MMA em MMC. Enquanto para Adélia esse foi um passo à frente, Luci teme que a mudança tenha sido prematura, sem ter levado em conta a identificação que as agricultoras têm com o MMA e com a ANMTR, na medida em que foram essas organizações que possibilitaram a implementação dos direitos previdenciários, que trouxe melhorias significativas na condição de vida das mulheres rurais.

Para Adélia, o uso da sigla MMC é mais que um passo à frente; é uma volta às origens, no sentido de reconhecer a condição camponesa das mulheres agricultoras. Em palestra proferida durante as comemorações do Dia Internacional da Mulher, em 2007, ela disse que, em seus grupos de estudo, as militantes foram buscar o significado da palavra "camponês" e descobriram que seria camponês aquele que produz a sua própria alimentação. Como uma das atuais bandeiras de luta das mulheres rurais é a soberania e a segurança alimentar, nada mais adequado do que se autodenominarem "camponesas". Para ela, a unificação dos movimentos autônomos foi uma mudança positiva.

Porque não é só Santa Catarina [...], nós estamos trabalhando a nível nacional, porque hoje somos um movimento nacional, né? A partir do 8 de março de 2004, nós somos o Movimento de Mulheres Camponesas do Brasil, antes [...] cada estado tinha a sua sigla, nós aqui em Santa Catarina era o MMA, no Rio Grande do Sul era a MMTR, no Paraná era MMTR e assim por diante, cada estado tinha a sua sigla, mas a partir do 8 de março de 2004 nós temos um movimento único a nível nacional, hoje estamos (presentes) em 19 estados [...] Em todas as capitais desses 19 estados as mulheres camponesas estão se concentrando, fazendo as suas atividades e em Brasília nós temos uma grande (parada) também, peitando com os órgãos públicos as nossas reivindicações (Em palestra na UFSC/Florianópolis, por ocasião da comemoração ao dia 08 de março, 05/03/2007).

Enquanto que para Luci: 
Não é a nomenclatura que muda a linha política. Sempre foi Movimento de Mulheres Agricultoras, de repente, MMC, Movimento de Mulheres Camponesas. Isso não foi compreendido. Pelas lideranças foi, mas pela base não [...], entre a minha compreensão e a compreensão da maioria tem diferença. No primeiro curso de formação, em 94, que eu fui, era o professor Ranulfo, nunca esqueci dele. Ele falou uma frase que eu lembro sempre: "Nem tudo, por mais correto, mais certo que seja pra mim, se eu não consigo ser compreendida e se ajustar com a maior parte, não vai ser aceito". Porque o seguinte, para as pessoas, elas já assimilavam Movimento de Mulheres Agricultoras, o movimento conquistou aposentadoria, conquistou salário-maternidade, não é fácil de tu mudar! Talvez um processo mais longo pra mudar de nome. (Luci Choinaski, entrevista concedida à Maria Ignez Paulilo e Cristiani Bereta da Silva, em 05/11/2008).

Ainda segundo Luci, há municípios nos estados do Sul do Brasil onde tanto está presente o MMC quanto o MMA. Informações esparsas que obtivemos de maneira assistemática confirmam essa afirmação. Ainda é cedo para se ter claro se a nova forma de se organizar e protestar dos movimentos de mulheres rurais reunidos no MMC será apenas um fator de exclusão dos grupos mais resistentes à mudança, ou se desta cisão resultará uma pluralidade de ações que poderá vir a ser benéfica para a conquista de maior igualdade e equidade social, especialmente de gênero, no meio rural brasileiro.

\section{Concluindo...}

As memórias sobre a organização das mulheres agricultoras em Santa Catarina oportunizam um exercício crítico de reflexão sobre as relações de poder, a busca pela igualdade, a transformação e o novo, mesmo que às apalpadelas. De todo modo, o que muitas narrativas trazem são elementos regulares que põem em perspectiva as relações de poder entre homens e mulheres, mas também entre mulheres e mulheres, tensões que evidenciam discursos cujos efeitos acabaram se encontrando de maneira bastante significativa no cotidiano de trabalho, nas relações familiares, 
afetivas e não menos políticas, importante notar. Espaços imprescindíveis ao processo de mudança que estava em curso. Para as mulheres agricultoras, até então, os espaços políticos legítimos eram as lides com a terra, com a casa, na Igreja e, quando muito, o envolvimento nas atividades comunitárias. Não era a rua, o Sindicato, o Partido Político ou mesmo a Pastoral da Terra. O que dizer então do Congresso Nacional?

Isso fica bem evidente quando observamos a participação das mulheres num outro movimento social, o MST. Na década de 1980, a própria formação de lideranças era dirigida aos homens e não às mulheres, pois a elas cabia discutir e solucionar problemas relativos aos lugares sociais relacionados às mulheres: saúde, creche, família, higiene. Inicialmente, não lhes dizia respeito discutir o título da terra, os empréstimos para o maquinário ou insumos, a previdência, a herança etc. (ver Silva, 2004). São relações de força que estão em jogo mais do que qualquer outra coisa. Relações de força que envolvem homens e mulheres, seus valores e noções de mundo, subjetividades que constroem diferenças de gênero, informam papéis, fixam posições, impõem hierarquias e disputam memórias.

A emergência de um movimento social só de mulheres e agricultoras provocou mudanças substantivas, a começar por elas mesmas, nas suas relações familiares, nas relações políticas etc. Mas também, e, sobretudo, revelaram novas questões a serem pensadas pelas instâncias do poder público a quem recorriam para reivindicar seus direitos ao longo das décadas de 1980 e 1990. A militância e a participação nesse movimento, em sindicatos e em partidos políticos foram apontando caminhos diferentes para Luci e Adélia. Luci seguiria sua militância pela via parlamentar e Adélia seguiu seu trabalho no MMA e, nos últimos anos, está entre as lideranças mais respeitadas do agora MMC. O processo de luta instaurado com força na década de 1980 segue de outra forma. A existência desses movimentos sociais, sobretudo os rurais, sob nosso ponto de vista, fez muito pelo deslocamento de percepções sobre as questões sociais, culturais e políticas. Eles certamente abriram possibilidades para que grupos sociais solapados em seus direitos pudessem lutar para consegui-los.

O uso de narrativas orais - longe do romantismo e da pretensão da "contra-história" da década de 1960 - constitui-se em metodologia de trabalho privilegiada quando nos detemos em estudos sobre movimentos sociais, como o MMA. Primeiro, porque este ocupa lugar num tempo bastante recente, sob domínio historiográfico de uma "história do tempo 
presente". Segundo, porque abre possibilidades de interpretação sobre "coisas do passado" - mesmo que recente -, a partir de testemunhos de sujeitos "que estavam lá". Evidente que, em nosso caso, não ignoramos o fato de que foram testemunhos realizados na condição de porta-vozes autorizados. Afinal, Luci Choinaski e Adélia Schmidt são referências importantes e legitimadas quando se trata do Movimento de Mulheres Agricultoras. Lembrando Paul Ricoeur, são testemunhas que se declaram testemunhas, nomeando a si mesmas como tais (e sendo nomeadas, importante dizer), construindo o "lá" em relação ao "aqui". (2007, p. 172174). Condição que implica, em parte, um aporte específico, mas não menos enriquecedor do ponto de vista da operação histórica. Mesmo que consideremos que fontes orais contam menos sobre eventos que sobre significados, as narrativas orais de Luci, Adélia e tantas outras militantes sempre serão capazes de nos surpreender, revelando aspectos desconhecidos de acontecimentos conhecidos, ressignificando questões ainda pouco exploradas nas pesquisas, enfatizando aspectos ainda pouco valorizados na escrita da história das mulheres camponesas, e, sobretudo, disputando memórias possíveis sobre si mesmas.

\section{Referências bibliográficas}

ALBERTI, Verena. Fontes orais: história dentro da História. In: PINSKY, Carla Bassanezi. (Org.) Fontes Históricas. $2^{a}$ ed. São Paulo: Contexto, 2006.

DE CERTEAU, Michel. A operação histórica. In: LE GOFF, Jacques e NORA, Pierre. Fazeer História: novos problemas. 2a edição. Rio de Janeiro: Bertrand Editora, 1987, p.17-58.

GOHN, M. da Glória. Movimentos sociais no início do século XXI: antigos e novos atores sociais. Petrópolis, Rio de Janeiro: Vozes, 2003.

HALBWACHS, Maurice. A memória coletiva. Trad. por Laís Teles Benoir. São Paulo: Centauro, 2004.

JOUTARD, Phillipe. Memória Coletiva. In : BURGUIÈRE, André (Org.). Dicionário das Ciências bistóricas. Trad. por Henrique Araújo Mesquita. Rio de Janeiro: Ed. Imago, 1993.

LAURINDO, Rosemeri. Luci Choinaski: a primeira camponesa eleita para o Congresso Nacional. Florianópolis: Paralelo 27, 1992.

NORA, Pierre. Entre memória e História: A problemática dos lugares. Projeto História. Revista do Programa de Estudos Pós-Graduados em História e do Departamento de História da PUC/SP. São Paulo, n.10, p. 7-40, dez./1993. 
POLLAK, Michael. Memória, esquecimento, silêncio. Estudos Históricos. Rio de Janeiro, v. 2, n. 3, p. 3-15, 1989.

RICOEUR, Paul. A memória, a bistória, o esquecimento. Tradução Alain François (et al.) Campinas: Editora da UNICAMP, 2007.

SCHERER-WARREN, Ilse. Das mobilizações às redes de movimentos sociais. Revista Sociedade e Estado. Brasília, vol. 21, n.1, p. 109-130, jan/abril de 2006.

SILVA, Cristiani Bereta da. Homens e mulheres em movimento: relações de gênero e subjetividades no MST. Florianópolis: Editora Momento Atual, 2004.

Resumo: O presente trabalho representa um esforço de análise e interpretação da história do Movimento de Mulheres Agricultoras em Santa Catarina - MMA, principalmente a partir das memórias de Luci Choinaski e Adélia Schmitz. Nesta operação, na qual utilizamos a metodologia da História Oral, debruçamo-nos sobre diferentes entrevistas realizadas entre 2000 e 2008, assim como em transcrições autorizadas de depoimentos, palestras, conferências realizadas, a partir da década de 1990, por essas mulheres em variadas situações. As memórias individuais, mais que nunca, neste caso, interpenetram-se com as memórias coletivas, sociais. Certamente o entorno da história de Luci e de Adélia não se reduzem a dos movimentos sociais. As relações possíveis ampliam o horizonte, oportunizando reflexões e análises sobre a própria história recente do Brasil.

Palavras-chave: história oral; memória; movimentos sociais.

\section{Oral History and Memory: Peasant Women's Social Movements}

Abstract: This paper constitutes an effort of analysis and interpretation of the history of the Peasant Women's Movement in contemporary Brazil, based mainly on Luci Choinaski and Adélia Schmitz's memories. For this we used the methodology of oral history, drawing on several interviews performed between 2000 and 2008 , on authorized transcriptions of oral statements, lectures and conferences given by the two from 1990 onwards on varied occasions. In this case more than ever individual memories intertwine with collective, social memories. Luci and Adelia's life trajectory cannot be accounted for solely by the history of social movements, but instead lead to a broadened horizon of analysis and reflection, covering the very recent history of Brazil.

Keywords: oral history; memory; social movements. 